Provided for non-commercial research and education use. Not for reproduction, distribution or commercial use.

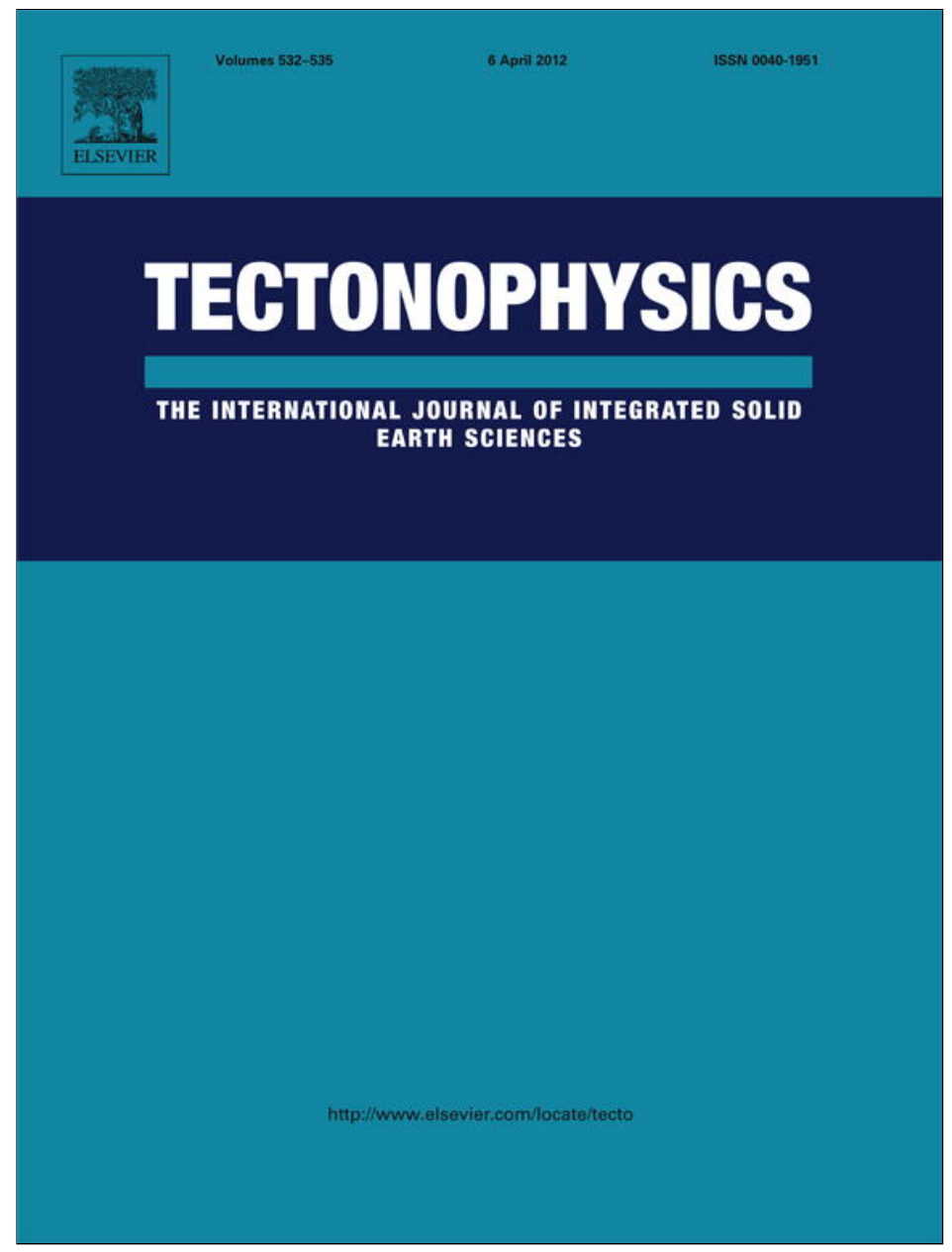

This article appeared in a journal published by Elsevier. The attached copy is furnished to the author for internal non-commercial research and education use, including for instruction at the authors institution and sharing with colleagues.

Other uses, including reproduction and distribution, or selling or licensing copies, or posting to personal, institutional or third party websites are prohibited.

In most cases authors are permitted to post their version of the article (e.g. in Word or Tex form) to their personal website or institutional repository. Authors requiring further information regarding Elsevier's archiving and manuscript policies are encouraged to visit:

http://www.elsevier.com/copyright 


\title{
Spatial and temporal evolution of $b$-values before large earthquakes in Taiwan
}

\author{
Chung-Han Chan ${ }^{a}$, Yih-Min Wu ${ }^{\text {a,* }}$, Tai-Lin Tseng ${ }^{a}$, Ting-Li Lin ${ }^{b}$, Chien-Chih Chen ${ }^{c}$ \\ a Department of Geosciences, National Taiwan University, Taipei 10617, Taiwan \\ ${ }^{\mathrm{b}}$ Department of Earth Sciences, National Cheng Kung University, Tainan 701, Taiwan \\ c Department of Earth Sciences and Graduate Institute of Geophysics, National Central University, Jhongli 32001, Taiwan
}

\section{A R T I C L E I N F O}

\section{Article history:}

Received 25 November 2010

Received in revised form 13 January 2012

Accepted 5 February 2012

Available online 18 February 2012

\section{Keywords:}

Gutenberg-Richter relation

$b$-value

Molchan diagram

Taiwan

\begin{abstract}
A B S T R A C T
We investigate the spatial and temporal variations of $b$-values before twenty-three earthquakes with $M_{L} \geq 6.0$ in the Taiwan region from 1999 to 2009. We estimate the spatial distribution of $b$-values within a one-year period before the occurrence of investigated earthquakes. It shows that the epicenters of those earthquakes are located predominately in the regions with low $b$-values relative to the entire study area. In terms of temporal evolutions, the $b$-values are slightly lower during the year prior to the investigated earthquakes in comparison to the periods two to five years earlier. We propose that these anomalies may offer spatiotemporal constraints for the earthquake forecasting in Taiwan in the future.
\end{abstract}

(C) 2012 Elsevier B.V. All rights reserved.

\section{Introduction}

The frequency-magnitude distribution (Ishimoto and Iida, 1939), also known as the Gutenberg-Richter relation (Gutenberg and Richter, 1954), in a seismogenic volume can be expressed as

$\log _{10} N=a-b \mathrm{M}$

where $M$ is magnitude, $N$ is the cumulative number of earthquakes with magnitude larger than $M$, and $a$ and $b$ are constants. The $b$-value represents the ratio of small to large earthquakes. In general, the $b$-value in broad seismic regions is close to 1.0 from global statistics (Lay and Wallace, 1995). For regions in smaller scale over a few to tens of kilometers, the temporal and spatial variations in $b$-values may be significantly large, ranging from 0.5 to 1.5 in Japan (Ogata and Katsura, 1993) and from 0.5 to 1.3 near Parkfield of the San Andreas fault (Schorlemmer et al., 2004).

Variation of $b$-value in a region is commonly correlated with characteristics of regional seismic activities. For example, high seismicity in magma chambers may be characterized by high $b$-values (Sanchez et al., 2004; Wiemer and McNutt, 1997). The initial rupture of large earthquakes, by contrast, was found to occur in regions where $b$ values are low (Wyss and Stefansson, 2006; Wyss et al., 2000). Previous studies (Schorlemmer et al., 2005, and references therein) pointed out that the region with low $b$-value implies large differential stress and suggests its being toward the end of the seismic cycle. Such relationship can be applied for evaluating seismic hazard and earthquake forecasting

\footnotetext{
* Corresponding author. Tel.: +88622362 0054; fax: +886223636095.

E-mail address: drymwu@ntu.edu.tw (Y.-M. Wu).
}

(Smith, 1981), even though the validity of earthquake prediction experiments remains controversial.

Due to collisions between the Philippine Sea Plate and the Eurasian Plate, numerous earthquakes have been taking place inland and off the east coast of the Taiwan Island. Most significant events that occurred in the past decades in Taiwan were well recorded and carefully studied by governmental bureau and research scientists. The $1999 M_{L}$ 7.3 Chi-Chi earthquake (earthquake No.1 in Fig. 1), for example, is the largest inland earthquake ever recorded in Taiwan. After the devastating Chi-Chi event, the $2003 M_{L} 6.4$ Chengkung earthquake (earthquake No.13 in Fig. 1) is the first event that occurred on the Longitudinal Valley fault of east coast with magnitude larger than 6 . Interestingly, both events were reported to be preceded by seismicity precursors such as noticeable decreases in regional seismicity rate and $b$-value (Chen, 2003; Chen et al., 2005; Wu and Chiao, 2006; Wu et al., 2008b). Those temporal decreases in regional seismicity rate and $b$-value may be explained by the quiescence in the seismicity with small magnitudes (Huang, 2006; Huang and Nagao, 2002; Huang et al., 2001). A detailed study by Wu et al. (2008b) also showed that the rupture region of the Chengkung earthquake had low $b$-value, similar to the observations in California (Wyss et al., 2000) and Iceland (Wyss and Stefansson, 2006). Those results motivated us to comprehensively investigate the spatial and temporal evolutions of $b$-values associated with the occurrence of large earthquakes in the whole Taiwan region.

\section{Seismic network and catalogue}

The Central Weather Bureau Seismic Network (CWBSN) is responsible for monitoring regional earthquakes in Taiwan. Since 1991, realtime digital recording has been performed; about 18,000 events each 


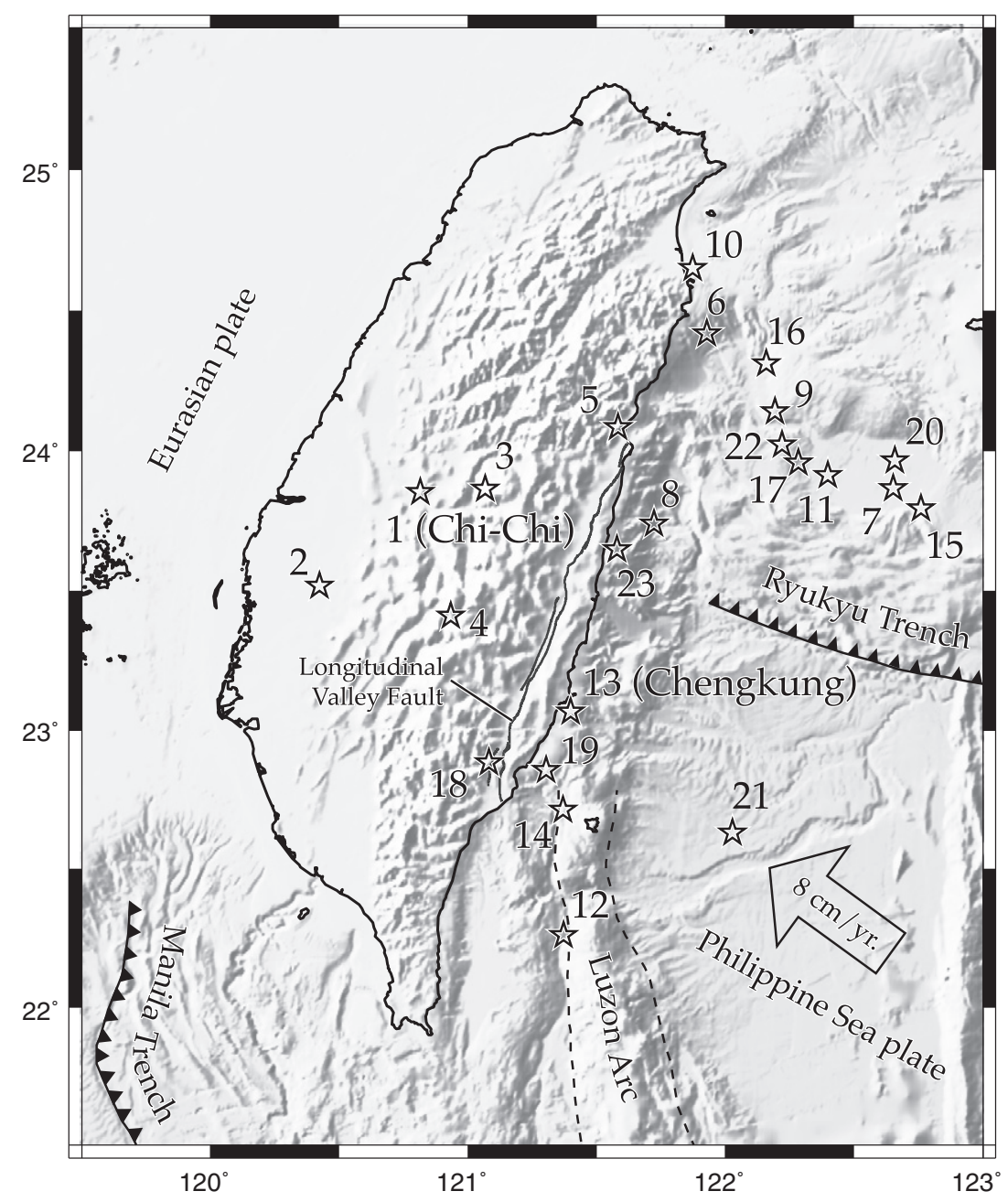

Fig. 1. Topographic map showing distribution of the 23 investigated earthquakes around Taiwan. We select earthquakes with $M_{L}$ greater or equal to 6.0 and focal depths less than $40 \mathrm{~km}$ during 1999 and 2009. Each of earthquakes is assigned a number according to the chronologic order of occurrence times. Gray lines represent the Longitudinal Valley fault, which is the boundary between Eurasia Plate and Philippine Sea Plate.

year in a roughly $400 \mathrm{~km} \times 550 \mathrm{~km}$ region are recorded (Wu et al., 2008a). The network currently consists of a central recording system with 71 telemetered stations (Fig. 2). The CWBSN instruments were operated in a triggered-recording mode until the end of 1993 when continuous recording began. $\mathrm{P}$ and $\mathrm{S}$ waves arrival times are picked manually for determination of earthquake parameters, i.e. hypocenter and Richter local magnitude $\left(M_{L}\right)$ (Shin, 1993).

The CWBSN has greatly enhanced the earthquake monitoring capability since the end of 1993 (Wu and Chiao, 2006). To evaluate the reliability of the catalogue, we calculate spatial distribution of magnitude of completeness $\left(M_{\mathrm{c}}\right)$ by using the maximum curvature approach (Wiemer and Wyss, 2000). We consider the catalogue in the period from the beginning of 1994 to the end of 2009 for shallow earthquakes (with focal depth $\leq 40 \mathrm{~km}$ ). We divide our study region into $0.2^{\circ} \times 0.2^{\circ}$ grids and search for the events within a circle of $30 \mathrm{~km}$ in radius (Fig. 2). The pattern of $M_{\mathrm{c}}$ simply reflects the density of the seismic stations (Mignan et al., 2011). The station densities are the highest in the northern and southwestern Taiwan, where the $M_{\mathrm{c}}$ can be as low as about 1.4. The $M_{\mathrm{c}}$ for the inland region is generally less than 2.0, whereas the $M_{\mathrm{c}}$ in the offshore region is between 2.5 and 3.2 due to poor network coverage. The spatial distribution and magnitudes estimated in this study is consistent with those obtained from the Bayesian magnitude of completeness method (Mignan et al., 2011). To achieve reliable $b$-values, it is important that we reevaluate $M_{c}$ according to the catalogue fulfill the same criterion of each $b$-value calculation.

\section{Distribution of $b$-values}

In this study, we investigate the $b$-value distributions before large events with $M_{L}$ greater than or equal to 6.0 and focal depths less than $40 \mathrm{~km}$ in the Taiwan region during 1999-2009. To avoid using earthquakes from the same sequence, we keep solely the first shock in a sequence as the investigated earthquake and exclude all other events that occurred within one month after and within inter-epicentral distances of $40 \mathrm{~km}$. There is a total of 23 earthquakes that fulfill (Fig. 1).

We first calculate the regional $b$-values for events with $M_{L} \geq M_{c}$ and focal depths less than $40 \mathrm{~km}$ in the region bounded by latitudes from $21.5^{\circ} \mathrm{N}$ to $25.5^{\circ} \mathrm{N}$ and longitudes from $119.5^{\circ} \mathrm{E}$ to $123.0^{\circ} \mathrm{E}$. We divide our study region into $0.2^{\circ} \times 0.2^{\circ}$ grids and search for the events within a circle of $30 \mathrm{~km}$ in radius, which is comparable to the rupture size for an event with magnitude 6.0 and above and is larger than the uncertainty in location of those earthquakes in the CWBSN catalogue. There are several methods proposed for computing $b$-values (e.g. Aki, 1965; Shi and Bolt, 1982). In this study, we use a maximum likelihood approach to estimate the $b$-values and the standard deviation (Aki, $1965)$ in the grids. The standard deviation $(\sigma)$ of $b$-value is as follows:

$\sigma=b N^{-1 / 2}$

where $N$ is number of the events used for $b$-value estimation.

We calculate the spatial distributions of $b$-values one year prior to the 23 investigated events (Fig. 3). To avoid temporal incompleteness 


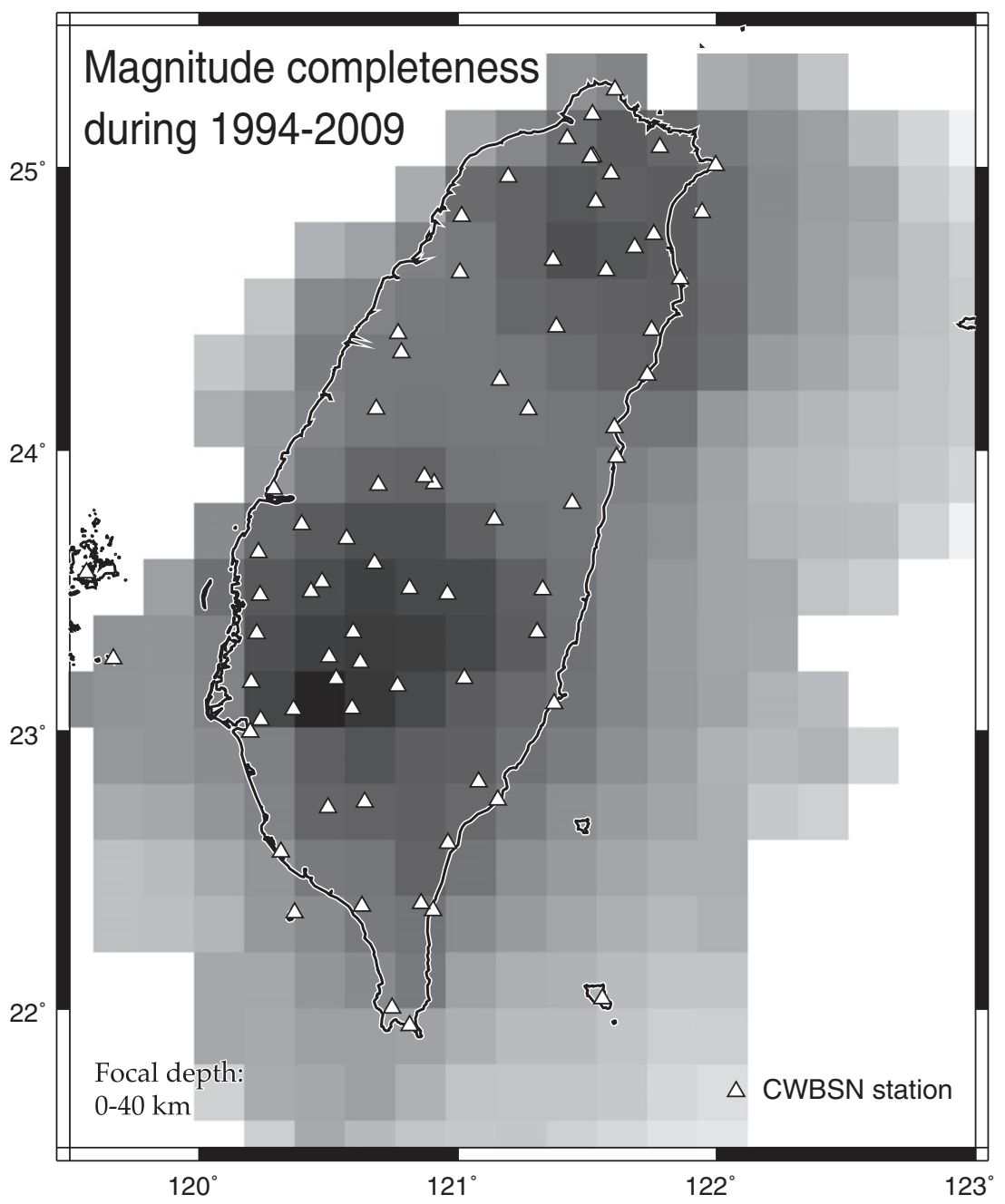

\section{$M_{C}$ according to seismic catalog from CWBSN}

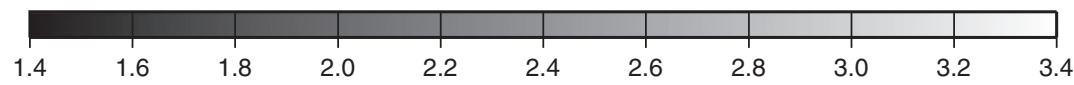

Fig. 2. Distribution of the magnitude completeness $\left(M_{c}\right)$ according to the catalogue acquired from the Central Weather Bureau Seismic Network (CWBSN). The white triangles show the locations of the CWBSN stations. Note that only cells with more than 100 events within the radius of 30 km are reported for reliability.

of catalogue after large earthquakes, we keep all events but exclude only the earthquakes within $24 \mathrm{~h}$ following the 23 studied earthquakes (Fig. 1) for $b$-value calculation. In order to acquire reliable results, only cells with more than 100 events within the radius of $30 \mathrm{~km}$ are reported. Due to insufficient number of seismicity, no $b$-values are reported in the grids where earthquakes Nos. 7, 12, 15, and 21 initiated. After excluding these disqualified cases, the epicentral $b$-values of 17 out of the remaining 19 (89\%) events are lower than 1.0 . We further compare the epicentral $b$-value of each investigated earthquake with those of the entire study area. For each event, we estimate the spatial fraction (relative to total area in percentage) that contains $b$ values equal to or lower than the epicentral $b$-value. In totality, we find that 16 out of 19 (84\%) earthquakes are located in the low $b$ regions that account for less than $50 \%$ of the study area (Fig. 3 ). For example, the 2003 Chengkung earthquake (earthquake No. 13) took place in the grid with $b$-value of 0.99 and there is $28 \%$ of study area having lower $b$-values than 0.99 (Fig. 3). Another representative is earthquake No. 22 that occurred on July 13th, 2009 offshore Taiwan. Its epicentral $b$-value is 0.73 and only $3 \%$ of study area has $b$-values lower than 0.73 (Fig. 3). Furthermore, even though when both standard deviations of the $b$-values for epicentral and study region are considered, 12 out of 19 (63\%) earthquakes are in the regions with lower $b$-values than the average in the study region.

We further employ the Molchan diagram to evaluate statistical significance of the argument that large earthquakes tend to occur in low $b$-value regions (Fig. 4). This diagram is originally designed for evaluation of earthquake forecasting ability and is presented as a fraction of space occupied by expectation against fraction of failure to predict (Molchan, 1990, 1991). We present "fraction of space occupied by expectation" as sorted events according to the proportion of study area having a $b$-value equal to or lower than those at the epicenters (presented in parentheses of each panel in Fig. 3). Thus, we define "expectation" as a presumed threshold of the proportion of study area having lower $b$-values within one year prior to occurrences of investigated events. The "fraction of failure to predict" indicates the proportion of the earthquakes with higher fraction of space occupied by expectation. That is to say, when the data points closely distributed along the diagonal line, it suggests distribution of the investigated earthquakes is independent of $b$-values; when a convex is presented, it suggests most of the earthquakes occurred in the regions with higher $b$-values in comparison to the entire area; whereas a concave suggests that most of the earthquakes occurred in the area with 

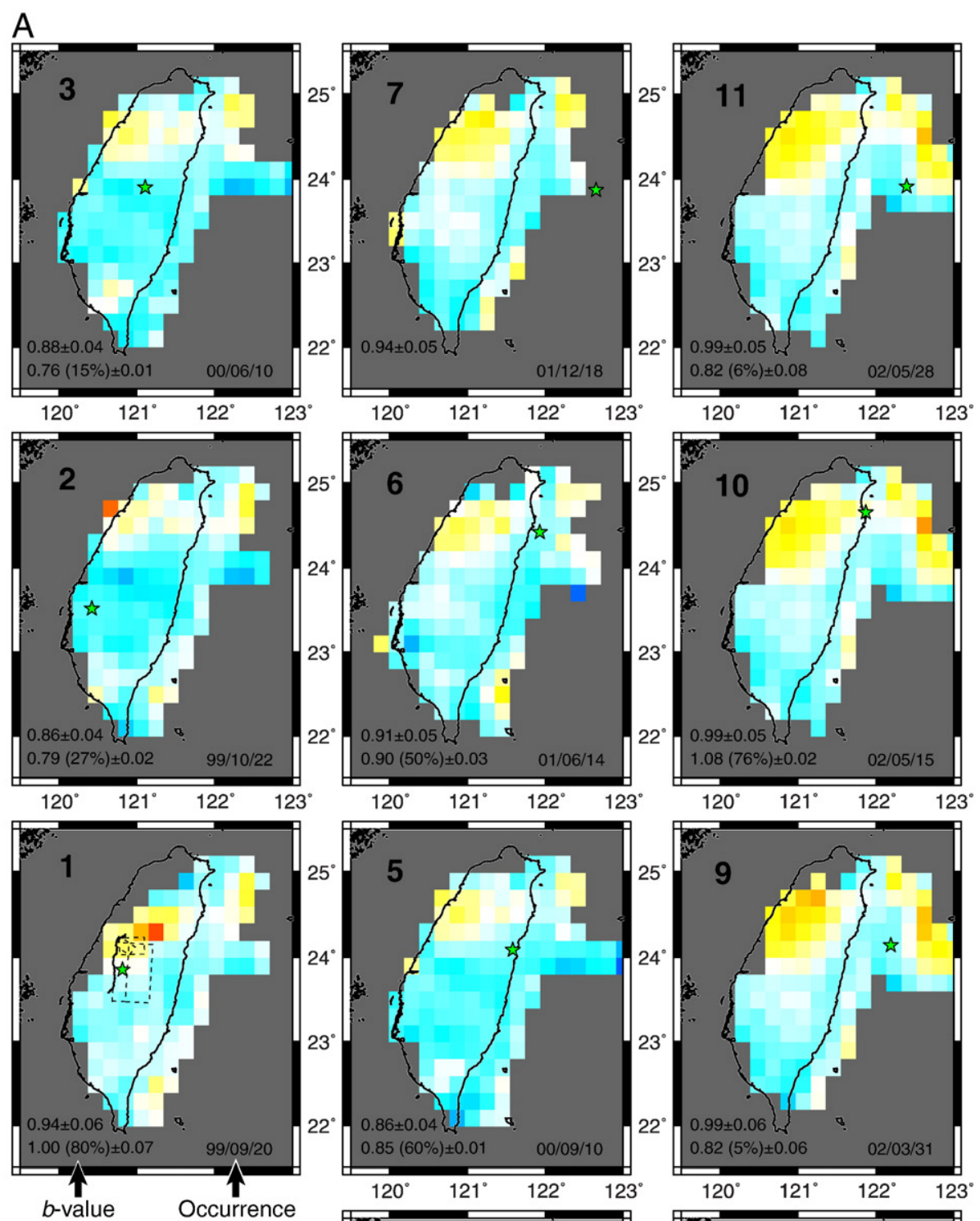

(\% of area with time of eqs. lower $b$-values) (yy/mm/dd)

Avg. $b$-value in
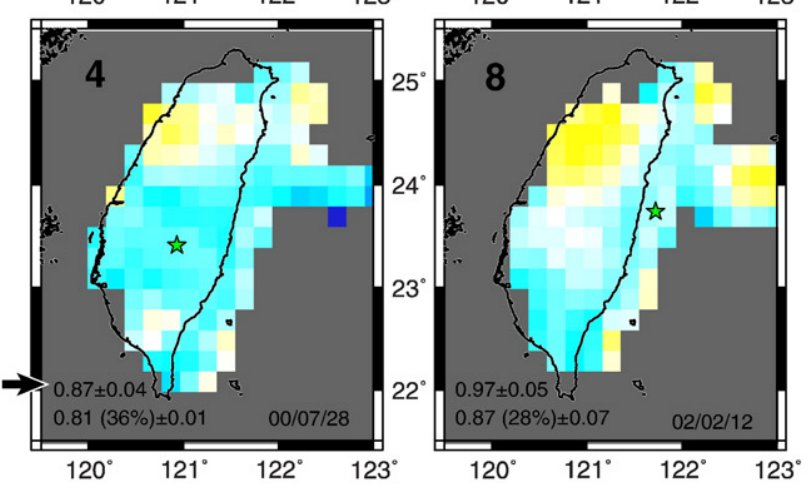

Distribution of $b$-values estimated by seismicity within 1 year before occurrence of each earthquake

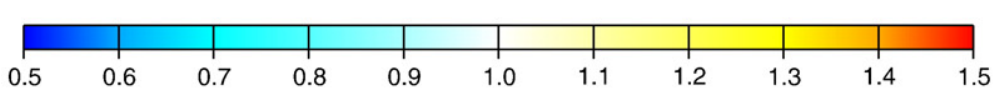

Fig. 3. Distribution of $b$-values estimated in one-year prior to the occurrence of 23 investigated earthquakes. Stars show the epicenter of earthquakes. The $b$-value with corresponding standard deviations in epicenter (lower line) and the study region (upper line) are presented in lower-left corner of each panel. The cells with less than 100 events in radius of $30 \mathrm{~km}$ are colored in grey reporting null $b$. Note that the areas with null $b$ are excluded for calculation. The proportion of study area having a $b$-value equal to or lower than those at the epicenters of the earthquakes are presented in parentheses of each panel. 

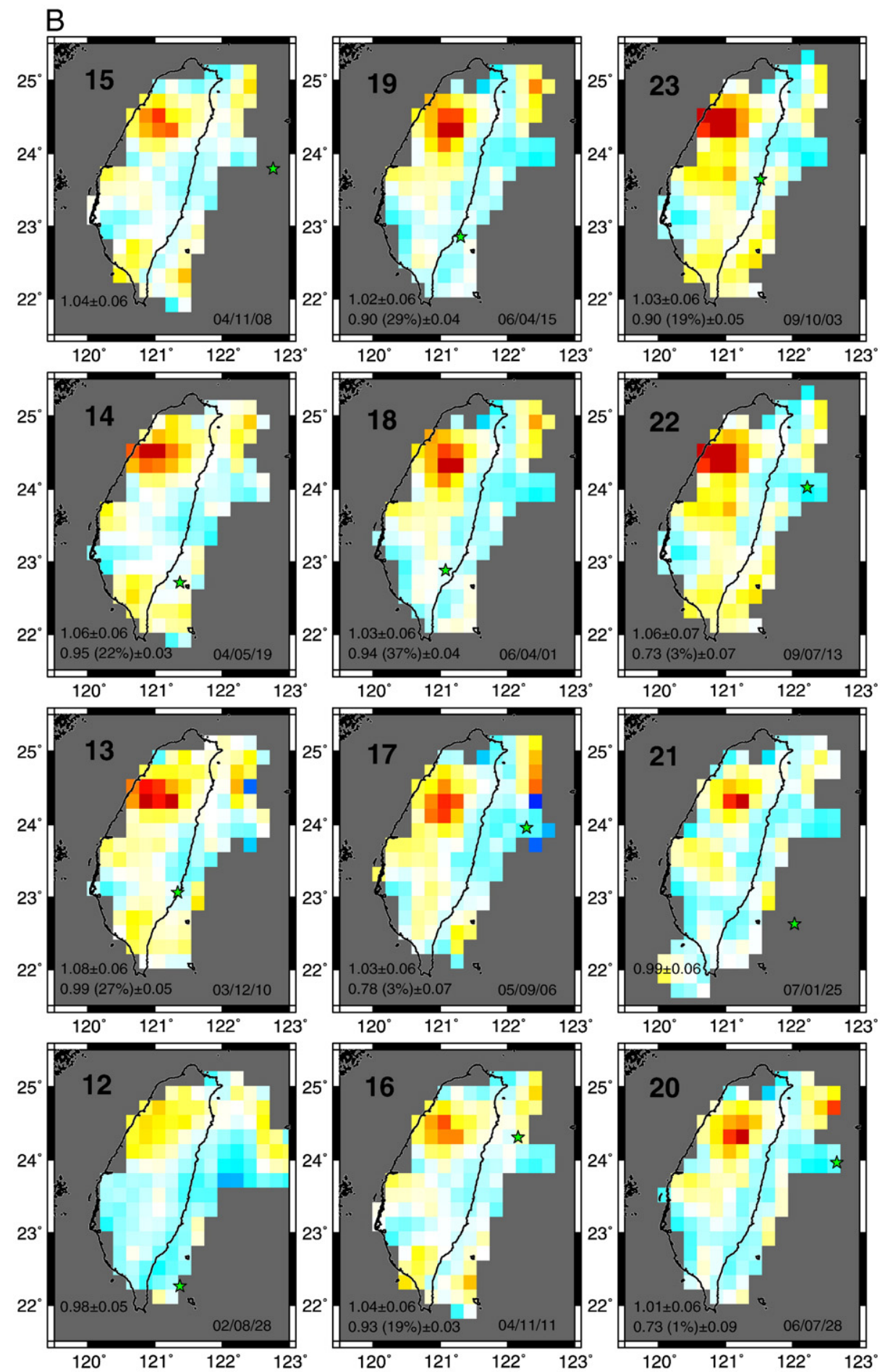

Distribution of $b$-values estimated by seismicity within 1 year before occurrence of each earthquake

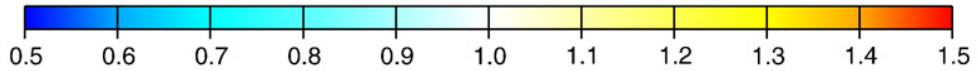

Fig. 3 (continued).

lower $b$-values. We confirm that such relationship of the low epicentral $b$-values exists when the standard deviations are taken into account.

In order to present a more reliable result in the Molchan diagram, we consider only the earthquakes in the grids where $b$-values are available. In other words, we do not consider earthquakes Nos. 7, 12, 15 , and 21 , which took place in grids without reported $b$-values due to insufficient number of seismicity. In the Molchan diagram (Fig. 4), the epicentral $b$-values of investigated earthquakes are significantly lower in comparison to the rest of study area. All of earthquakes are located 


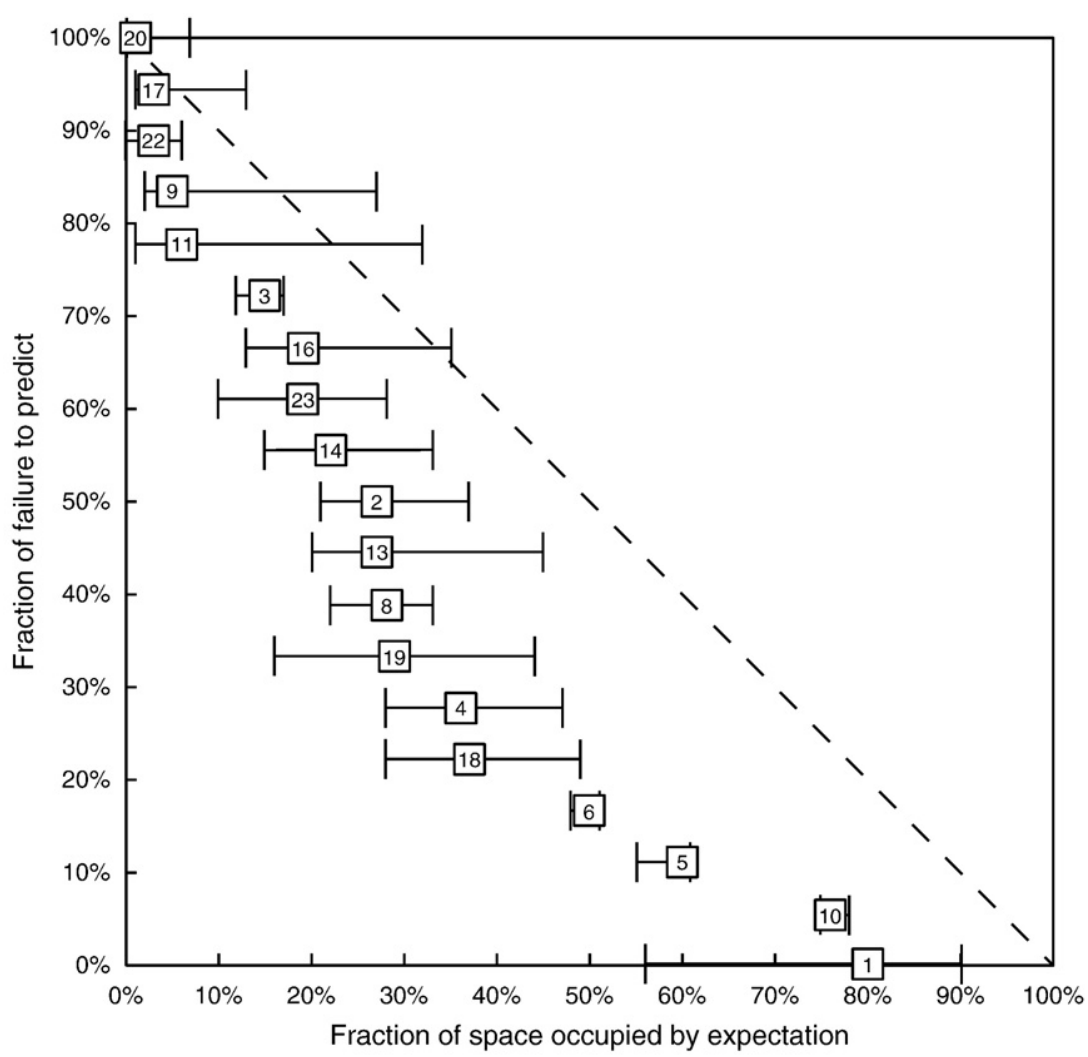

Fig. 4. Molchan diagram for investigating corresponding $b$-value at each epicenter compared with the entire study area. Numbers in the rectangles represent the corresponding number of the earthquake as shown in Fig. 1. The error bar for each earthquake represents corresponding fraction of space for the standard deviation of the $b$-value calculation (shown in Fig. 3).

in the region with lower $b$-values than at least $25 \%$ of the entire study area (i.e. $75 \%$ of study area having a $b$-value equal to or lower than those at all of the epicenters of the earthquakes). For the $1999 M_{L} 7.3$ Chi-Chi earthquake (earthquake No. 1 ), if we further consider earthquakes within the true ruptured region of ca. $40 \mathrm{~km} \times 80 \mathrm{~km}$ (Johnson and Segall, 2004) (Fig. 3), the $b$-value of the entire rupture zone becomes 0.92 (c.f. the epicentral $b$-value of 1.00 for the Chi-Chi earthquake), which suggests only $40 \%$ of the study area having lower $b$ value than in the rupture zone.

To examine temporal variation of the $b$-values around epicentral regions, we consider five different time periods prior to the occurrences of the earthquakes (Fig. 5). In order to acquire reliable results, we only consider the investigated earthquakes with more than 100 events within the radius of $30 \mathrm{~km}$ in the time windows. We also reevaluated $M_{c}$ according to the catalogue in the corresponding periods. It clearly demonstrates that the $b$-values are very stable $(0.90-0.93)$ during the time windows from five to one year(s) prior to the occurrence of earthquakes. It then drops by ca. $5 \%$ within a year before earthquakes. By considering standard deviations, however, the temporal evolutions of the $b$-values become trivial.

\section{Discussions and conclusions}

For the Gutenberg-Richter relation, magnitude cutoffs may play an important role for determination of $b$-value. In order to test the reliability of our results, we present biases of the $b$-values by considering different magnitude cutoffs for the calculation (Fig. 6). When the differences between magnitude cutoff and $M_{c}$ are in between -0.1 and +0.5 , the results show that change of the $b$-values are smaller than 0.03 . In contrast with the averaged standard deviation of 0.04 for $b$-values, the biases imparted by considering different magnitude cutoffs are insignificant when the cut-off magnitude is close or above $M_{c}$. Note that the deviations of the $b$-value changes become larger when higher magnitude cutoffs are considered. It can be attributed to fewer data for $b$-value calculations. When lower magnitude cutoffs are considered, systematical lower $b$-values are acquired, which can be associated with incomplete catalogue. It should be mentioned that since the $M_{c}$ in this study is acquired by the maximum curvature approach (Wiemer and Wyss, 2000), $M_{c}$ is seldom overestimated, i.e. minimum magnitude should not be smaller than $M_{c}$.

Our observations of the relatively low spatial $b$-values for the epicentral areas are in good agreement with the results presented by Wyss et al. (2000) and Wyss and Stefansson (2006), who argued that the initiations of large earthquakes may be mapped by low $b$ values. Many studies have considered the $b$-value as a monitoring index related to forthcoming large earthquakes (e.g. Ogata and Katsura, 1993; Papadopoulos et al., 2010). Main et al. (1989) showed that $b$-value varies between 0.5 and 1.5 during the earthquake cycle and proposed that critical failure in a large earthquake should occur in regions with $b=0.5$. They also discussed $b$-value evolution for laboratory creep experiments and seismicity during the 1984 Western Nagano, Japan (Figs. 1d and 3 in Main et al. (1989)). Their studies examined decreases in the $b$-value as stress increases before failure of faults. Further investigation for the southern Californian region also supports that seismicity preceding large main shocks can be associated with low $b$-values (Henderson et al., 1994).

From previous analysis on the seismicity in the Taiwan region (Wu and Chiao, 2006; Wu et al., 2008b), the relatively low seismicity rate and the temporal decrease in the $b$-values before large earthquakes in Taiwan may be considered as a forecasting indicator associated with the quiescence in the seismicity with small magnitudes. Our results further show that the 2003 Chengkung earthquake (earthquake No. 13) took place in a grid with a $b$-value of 0.99 , which is lower than $72 \%$ of the region (Fig. 3), and is consistent with the observations reported in Wu et al. (2008b). We also found that several earthquakes, both inland and offshore of Taiwan, have 


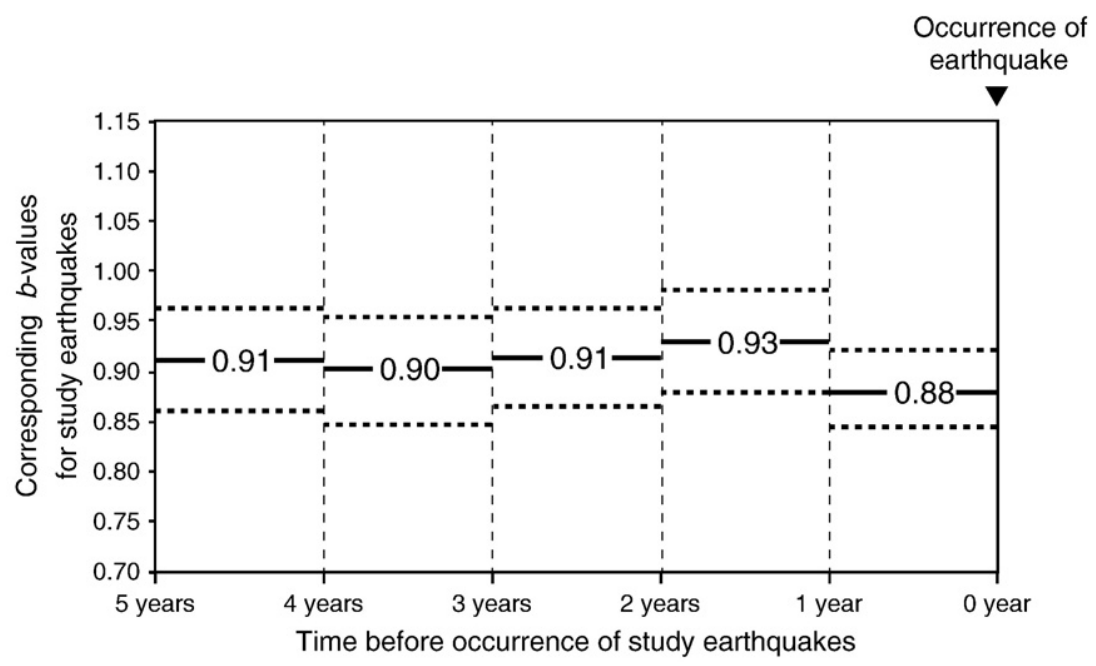

Fig. 5. Average of epicentral $b$-values (solid lines) and standard deviations (dash lines) for the 23 investigated earthquakes in different time windows. In order to acquire reliable results, we only consider the investigated earthquakes with more than 100 events within the radius of $30 \mathrm{~km}$ in the time windows.

fairly low epicentral $b$-values (Fig. 3). One of the lowest values is found to be 0.73 for the earthquake No. 22 as shown in Fig. 3. Overall, the epicentral $b$-values for 17 out of 19 (89\%) events are lower than 1.0. Through the Molchan diagram (Fig. 4), we show that the low $b$ values in epicenter regions are statistically significant.

It is worth noting that the epicenter of the $1999 M_{L} 7.3$ Chi-Chi earthquake is in a region with an unexpectedly high $b$-value of 1.00 in the year prior to the shock (earthquake No. 1 in Fig. 3). If we evaluate the $b$-value in its rupture area, which is acquired by Johnson and
Segall (2004), we find a somewhat low $b$-value of 0.92 , which correspond to $40 \%$ of study area with lower $b$-value. This implicitly suggests that decreases in $b$-value, which imply an increase in stress (Main et al., 1989), may take place in the entire rupture fault zones of large earthquakes, but not at the rupture initiations.

We also evaluate temporal variations of the $b$-values before the occurrences of investigated earthquakes (Fig. 5). It shows that epicentral $b$-values (0.90-0.93) are already lower than in broad seismic regions during the time windows of five to one year prior to the

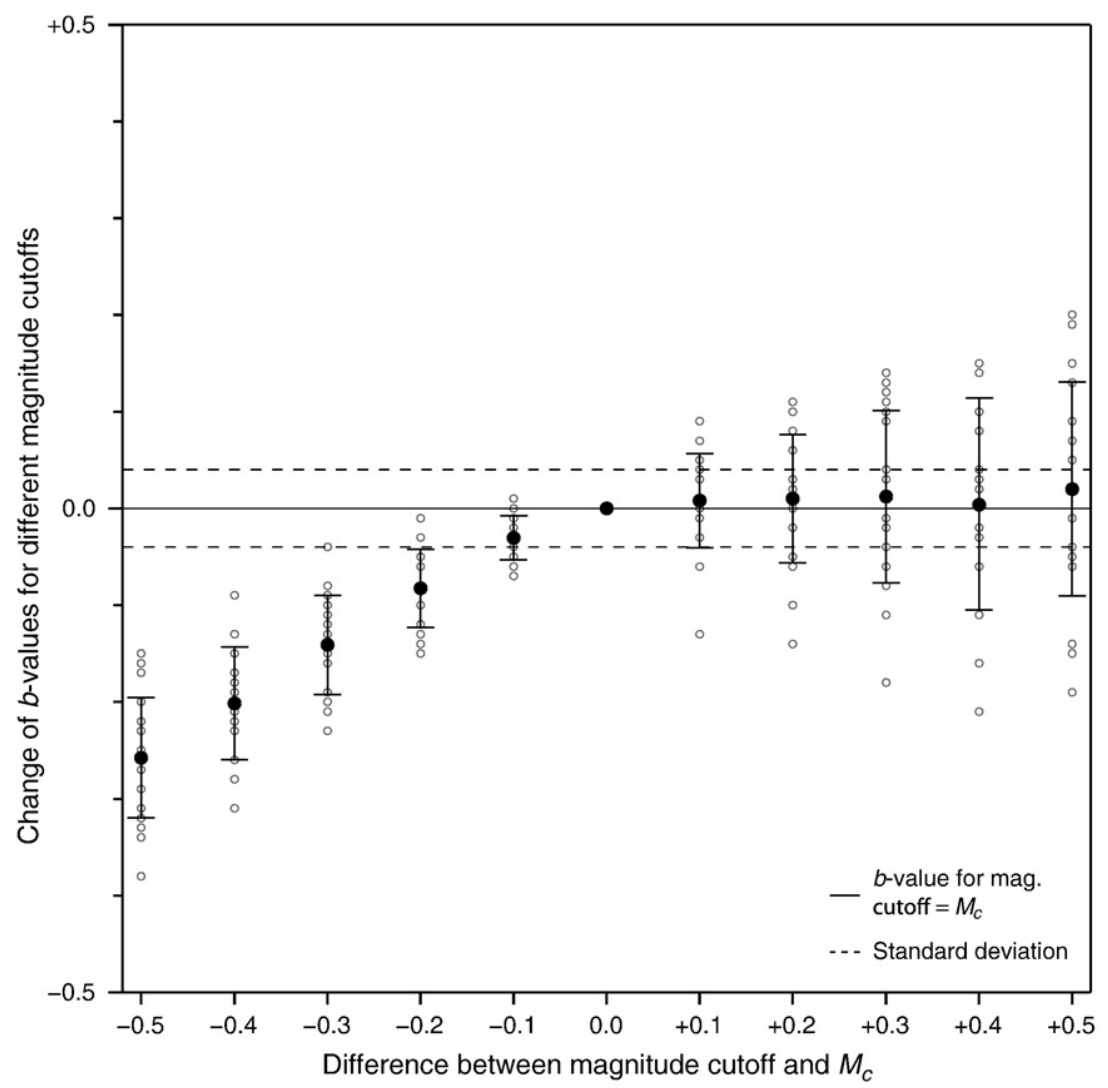

Fig. 6. Change of epicentral $b$-values caused by different magnitude cutoffs for the investigated earthquakes. The solid line and dash lines represent mean and standard deviation (0.03) of $b$-value calculation when magnitude cutoff is equal to $M_{c}$, respectively. Open circles represent $b$-value differences using different magnitude cutoffs for the investigated earthquakes. Solid circles and error bars represent average difference and standard deviation of the change, respectively, using different magnitude cutoffs. 
target earthquake (where $b$-value from global statistics is close to 1.0 (Lay and Wallace, 1995)). Further drop of $b$-values by $4 \%$ is observed for one year before the investigated earthquakes, although this evolution is relative small in comparison with the standard deviation. This suggests that monitoring the evolution of $b$-values may provide spatial and temporal constraints for the forthcoming strong earthquakes consistently in both of long-term and short-term periods.

\section{Acknowledgments}

This research was supported by the Central Weather Bureau and the National Science Council (NSC99-2811-M-002-123, NSC992119-M-002-022, NSC99-2627-M-002-015, NSC100-3114-M-002001, and NSC99-2116-M-002-006) of the Republic of China. We also appreciate the constructive comments provided by editor and two anonymous reviewers.

\section{References}

Aki, K., 1965. Maximum likelihood estimate of $\mathrm{b}$ in the formula $\log \mathrm{N}=\mathrm{a}-\mathrm{bM}$ and its confidence. Bulletin Earthquake Research Institute University Tokyo 43, 237-239.

Chen, C.C., 2003. Accelerating seismicity of moderate-sized earthquakes before the 1999 Chi-Chi, Taiwan, earthquake: testing time-prediction of self-organizing spinodal model of earthquakes. Geophysical Journal International 155, F1-F5.

Chen, C.C. Rundle, J.B. Holliday, J.R., Nanjo, K.Z, Turcotte, D.L, Li, S.C. Tiampo, K.F. 2005. The 1999 Chi-Chi, Taiwan, earthquake as a typical example of seismic activation and quiescence. Geophysical Research Letters 32, L22315.

Gutenberg, B., Richter, C., 1954. Seismicity of the Earth and Associated Phenomena, 2nd ed. Princeton Univ. Press, Princeton, N.J. (310 pp.)

Henderson, J., Main, I.G., Pearce, R.G., Takeya, M., 1994. Seismicity in north-eastern Brazil fractal clustering and the evolution of the $b$-value. Geophysical Journal International $116,217-226$

Huang, Q., 2006. Search for reliable precursors: a case study of the seismic quiescence of the 2000 western Tottori prefecture earthquake. Journal of Geophysical Research 111, B04301. doi:10.1029/2005JB003982.

Huang, Q., Nagao, T., 2002. Seismic quiescence before the $2000 \mathrm{M}=7.3$ Tottori earthquake. Geophysical Research Letters 29, 1578

Huang, Q., Sobolev, G.A., Nagao, T., 2001. Characteristics of the seismic quiescence and activation patterns before the $M=7.2$ Kobe earthquake, January 17, 1995. Tectonophysics $337,99-116$

Ishimoto, M., Iida, K., 1939. Observations of earthquakes registered with the microseismograph constructed recently. Bulletin Earthquake Research Institute Tokyo University $17,443-478$

Johnson, K.M., Segall, P. 2004. Imaging the ramp-décollement geometry of the Chelungpu fault using coseismic GPS displacements from the 1999 Chi-Chi, Taiwan earthquake. Tectonophysics 378, 123-139.
Lay, T., Wallace, T.C., 1995. Modern Global Seismology. Academic Press, p. 393. Main, I.G., Meredith, P.G., Jones, C., 1989. A reinterpretation of the precursory seismic $b$-value anomaly from fracture mechanics. Geophysical Journal 96, 131-138.

Mignan, A., Werner, M.J., Wiemer, S., Chen, C.-C., Wu, Y.-M., 2011. Bayesian estimation of the spatially varying completeness magnitude of earthquake catalogs. Bulletin of the Seismological Society of America 101,1371-1385. doi:10.1785/0120100223.

Molchan, G.M., 1990. Strategies in strong earthquake prediction. Physics of the Earth and Planetary Interiors 61, 84-98.

Molchan, G.M., 1991. Structure of optimal strategies in earthquake prediction. Tectonophysics 193, 267-276.

Ogata, Y., Katsura, K., 1993. Analysis of temporal and spatial heterogeneity of magnitude frequency distribution inferred from earthquake catalogues. Geophysical Journal International 113, 727-738.

Papadopoulos, G.A., Charalampakis, M., Fokaefs, A., Minadakis, G., 2010. Strong foreshock signal preceding the L'Aquila (Italy) earthquake $\left(M_{w} 6.3\right)$ of 6 April 2009. Natural Hazards Earth System Science 10, 19-24. doi:10.5194/nhess-10-19-2010.

Sanchez, J.J., McNutt, S.R., Power, J.A., Wyss, M., 2004. Spatial variations in the frequency-magnitude distribution of earthquakes at Mount Pinatubo volcano. Bulletin of the Seismological Society of America 94, 430-438.

Schorlemmer, D., Wiemer, S., Wyss, M., 2004. Earthquake statistics at Parkfield: 1. Stationarity of $b$-values. Journal of Geophysical Research 109, B12307. doi:10.1029/2004JB003234.

Schorlemmer, D., Wiemer, S., Wyss, M., 2005. Variations in earthquake-size distribution across different stress regimes. Nature 437 (22), 539-542.

Shi, Y., Bolt, B.A., 1982. The standard error of the magnitude-frequency $b$ value. Bulletin of the Seismological Society of America 72, 1677-1687.

Shin, T.C., 1993. The calculation of local magnitude from the simulated Wood-Anderson seismograms of the short-period seismograms. Terrestrial, Atmospheric and Oceanic Sciences 4, 155-170.

Smith, W.D., 1981. The b-values as an earthquake precursor. Nature 289, 136-139.

Wiemer, S., McNutt, S., 1997. Variations in frequency-magnitude distribution with depth in two volcanic areas: Mount St. Helens, Washington, and Mt. Spurr, Alaska. Geophysical Research Letters 24, 189-192.

Wiemer, S., Wyss, M., 2000. Minimum magnitude of completeness in earthquake catalogs: examples from Alaska, the Western United States, and Japan. Bulletin of the Seismological Society of America 90 (4), 859-869.

Wu, Y.M., Chiao, L.Y., 2006. Seismic quiescence before the 1999 Chi-Chi, Taiwan Mw7.6 earthquake. Bulletin of the Seismological Society of America 96, 321-327.

Wu, Y.M., Chang, C.H., Zhao, L., Teng, T.L., Nakamura, M., 2008a. A comprehensive relocation of earthquakes in Taiwan from 1991 to 2005. Bulletin of the Seismological Society of America 98, 1471-1481. doi:10.1785/0120070166.

Wu, Y.M., Chen, C.C., Zhao, L., Chang, C.H., 2008b. Seismicity characteristics before the 2003 Chengkung, Taiwan Mw6.8 earthquake. Tectonophysics 457, 177-182. doi:10.1016/j.tecto.2008.06.007.

Wyss, M., Stefansson, R., 2006. Nucleation points of recent mainshocks in Southern Iceland, mapped by b-values. Bulletin of the Seismological Society of America 96, 599-608.

Wyss, M., Schorlemmer, D., Wiemer, S., 2000. Mapping asperities by minima of local recurrence time: the San Jacinto-Elsinore fault zones. Journal of Geophysical Research $105,7829-7844$ 